\title{
DEVELOPMENT OF VISUAL EVALUATION AND NUMERICAL ANALYSIS SYSTEM OF BLAST FURNACE
}

\author{
Shinroku Matsuzaki*, Masahiro Ito*, Kazumoto Kakiuchi*, Makoto Iosbe* \\ * Nippon Steel Corporation
}

\begin{abstract}
Data the measurement sensor installed with spatial distribution on the blast furnace were successively accumulated online from the process computer to the database system over a long period. This is a new system that accurately considers the relation with the installation position of each sensor, and picture computerization of the measurement data was developed. The overall operation state of a blast furnace, which skilled operators can see in their mind's eye, was objectively visualized as pictorial information. Copyright (C) 2005 IFAC
\end{abstract}

Keywords: Computer graphics, Industrial control, Process control, Steel manufacture, Sensors

\section{INTRODUCTION}

Techniques to quantitatively analyze and control conditions inside a blast furnace have been established thanks to technical advances such as the development of various physical models (Yagi et al., 1983; Takatani, 1995; Nogami, 2003; Sugiyama et al., 1987) and application of artificial intelligence, or AI (Takarabe et al., 1989; Niwa et al., 1989).

To further stabilize the operation of blast furnaces, it is necessary to further quantitatively evaluate and analyze non-steady behavior (dynamic behavior and characteristics) of the phenomena that take place in blast furnaces. As an example of these attempts, a 3dimensional non-steady physical model (Takatani et al., 1999) is now being developed.

A variety of sensors to directly measure the internal temperature, pressure and other conditions of a blast furnace have been developed, and they have significantly contributed to clarifying what occurs in a blast furnace. In addition, various sensors are provided on the shell of a blast furnace for the continuous, long-term measurement of temperature, etc., but these sensors measure conditions inside a furnace only indirectly from outside the shell of the furnace.

Based on long-term experience, a blast furnace operator judges the operating conditions of a furnace by comprehensively evaluating data obtained through direct interior furnace measurement and indirect shell measurement. Thus, understanding and predicting especially non-steady phenomena of blast furnaces depend largely on the experience and skill of the furnace operators. In this situation, we believe that to further stabilize blast furnace operation and decrease the consumption ratio of reducing agents, it is necessary to develop a technology to quantitatively evaluate the non-steady phenomena of blast furnaces, a modeling technology, and a system that flexibly and adequately provides operation guidance based on quantitative evaluation. As the first step toward this end, we developed a visual evaluation and numerical analysis system for blast furnaces as a new technology to integrate and quantitatively evaluate data from many temperature and pressure sensors installed in various positions in a blast furnace. 
The developed system is characterized by a new approach to that regard regards a blast furnace furnaces as a using a distributed parameter system process of distributed parameter system having with 3-dimensional distribution characteristics, and that quantify quantifies the non-steady behavior of furnace phenomena from this view point viewpoint.

Although the measurement data from various sensors on a blast furnace were conventionally input to a process computer, they were not always fully analyzed quantitatively from the above viewpoint and were discarded after a certain time period for reasons including:

1) There was no hardware or a database system capable of storing great amounts of measurement data taken at short sampling intervals over a long period of time.

2) There was no technique provided to efficiently analyze vast amounts of accumulated measurement data or quantitatively evaluate the operating conditions (3-dimensional distribution characteristics, non-steady phenomena, etc.) of a blast furnace based on the analysis.

The new system has been developed while taking advantage of the latest remarkable advances in computer technology, the wide availability of economical hardware and database systems capable of accumulating vast amounts of digital data and the enhancement and wider application of digital image processing technologies. The system incorporates as its foundation technologies to store great amounts of blast furnace operation data taken at as short sampling intervals as possible over a long time period and to process the furnace operation data into visual information.

This paper outlines the following components of the developed system: the technology to process blast furnace operation data into visual information; and the spatial differential vectors of shaft pressure, which have been newly defined as products of the secondary manipulation of the visual information.

\section{OUTLINE OF BLAST FURNACE PROCESS AND LIMITATIONS OF CONVENTIONAL ANALYSIS TECHNIQUES}

A blast furnace is a moving-layer-type counter-flow reaction vessel with the following features: iron ore and coke, both in grains, are charged from its top portion after the other to form a pile of their layers one over the other; a blast of hot air is blown in through the blast injection nozzles (tuyeres) in its lower portion, and the hot air makes the coke burn to generate high-temperature reduction gas; and iron oxide in the iron ore is reduced and melted by the high-temperature reduction gas into molten pig iron. This reaction vessel is a vertical, cylindrical pressure vessel with a larger diameter in the middle and composed of five sections, namely a throat, a shaft, a belly, a bosh and a hearth, in that order, from top to bottom. The shaft and the bosh have a truncated cone shape (see Fig. 1).

The tuyeres are provided in tens of units along the circumference of the furnace, and the air blown in through them at high temperature and pressure forms in front of them a space called the 'raceway,' where coke in a coke-packed zone inside the tuyeres burns while moving spirally.

In the lumpy zone in the upper part of the blast furnace, the ore and coke charged from the furnace top gradually slide down as the charged materials are consumed in the lower part of the furnace, and in the meantime, the ore is heated and reduced by the reducing gas.

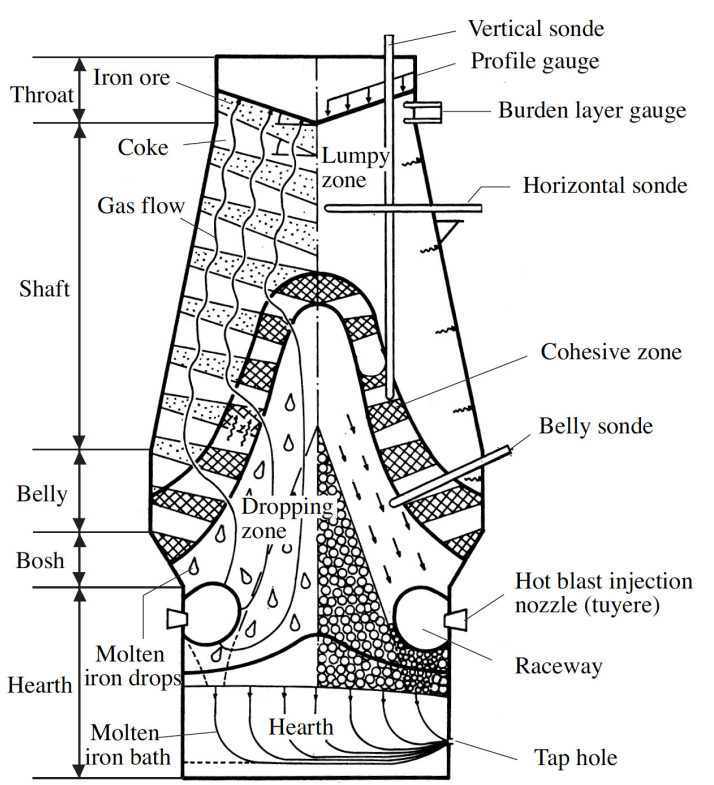

Fig. 1. Outline of blast furnace process

In the belly, as iron ore is heated and reduced, the viscosity of ore grains lowers, and they begin to soften and then fuse to form what is called a 'cohesive zone.' Since the porosity of the fused ore grains is low, the permeability of the cohesive zone is also low. Thus, the cohesive zone has a structure in which layers of the low-permeability ore and those of the high-permeability coke (coke slits) are piled one over the other.

In the dropping zone, which is the space just under the cohesive zone, molten metal and slag formed at the lower boundary of the cohesive zone drop down through a coke-packed layer and a central cone of coke called a 'deadman' into a bath of molten iron in the hearth, with molten slag floating on its surface. The molten iron and slag are then discharged to the outside of the furnace through a tap hole. 
The gas flow in a blast furnace and the formation of the cohesive zone, which are factors essential for furnace operation, depend on the distribution of the ore/coke ratio in the radial direction. When the ore/coke distribution is adequately regulated using burden distribution control techniques, the distribution of the gas flow rate inside the blast furnace, the shape of the cohesive zone, the thermal loads near the furnace shell, etc. are appropriately controlled. Whether these are appropriately controlled can be judged by analyzing and evaluating the data from the temperature and pressure sensors at various positions in the furnace.

However, a blast furnace is a huge shaft furnace, and the spatial distribution of phenomena that take place inside varies not only in the radial direction but also in the vertical and circumferential (or azimuthal) directions. If measurement data from some sensors in a certain section of the blast furnace are analyzed simply in the form of a chart of independent time trends as shown in Fig. 2, for instance, the spatial distribution characteristics of blast furnace phenomena and their non-steady behavior cannot be accurately understood.

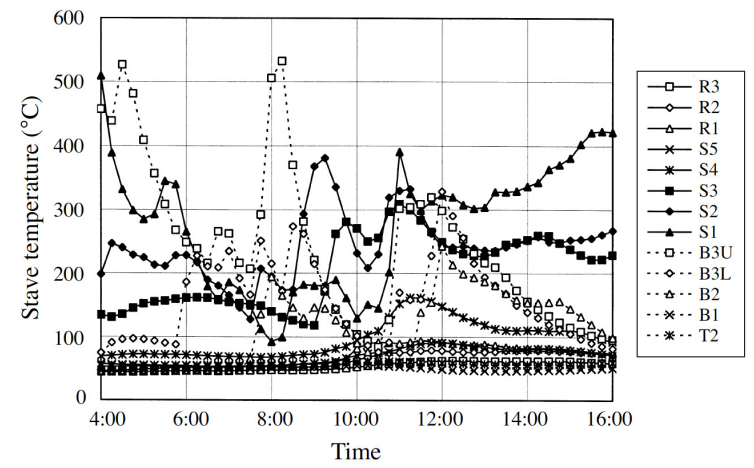

Fig. 2. Time trends in stave temperature distribution in furnace height direction (covering $180^{\circ}$ of azimuthal angle)

\section{VISUAL EVALUATION AND NUMERICAL ANALYSIS SYSTEM OF THE BLAST FURNACE}

The developed system comprises 1) a database system to store measurement data, which are input to the process computer from many sensors at intervals over a long time period, in the form of digital data and 2) a software package to process the measurement data into visual information and apply secondary manipulations to the visual information on a personal computer (PC). The database system and the $\mathrm{PC}$ are connected to the process computer through a network, enabling on-line data analysis. It is also possible using this system to extract any part of the accumulated digital data from the database system as required and analyze them off-line.

\subsection{Technique to visualize blast furnace operation data (Ito et al., 2002; Matsuzaki et al., 2002)}

This technique is characterized by: visualizing the spatial distribution characteristics of measurement data from the sensors at various positions in the blast furnace in the form of 2-dimensional graphic information comprising isograms of the measurement data; and analyzing time trends in the visualized data in the form of moving images.

Specifically, the process of this technique is as follows. The wall surface of the blast furnace is unfolded and projected onto a 2-dimensional plane where the ordinate and abscissa represent the height and circumference, respectively, of the furnace. The measurement data of each sensor are plotted on the said plane at a position precisely corresponding to the position of the sensor from which the data came. Based on the above, an isogram chart comprising curves that link the positions with the same values of a measurement data item and a vector chart are generated. A virtual grid reflecting the required spatial resolution is drawn covering the areas of the plane where there are no sensors, and the value of a grid point is calculated by spatial interpolation based on the measurement data of the sensors located near the point and the actual 3-dimensional distances from these sensors.

The sensors are not necessarily distributed evenly on the projection plane, and, to cope with this, algorithms to perform spatial interpolation at high speeds and draw isograms capable of dealing with any chosen sensor position and realizing on-line analysis were developed.

Figure 3 shows visualization examples of the temperature of the staves covering the area of the shell of the blast furnace, the internal furnace pressure in its shaft and the temperature of its hearth wall. Note that, in relation to the above, the pressure in front of the tuyeres was estimated considering the pressure loss from the hot-blast mains to the blowpipes.
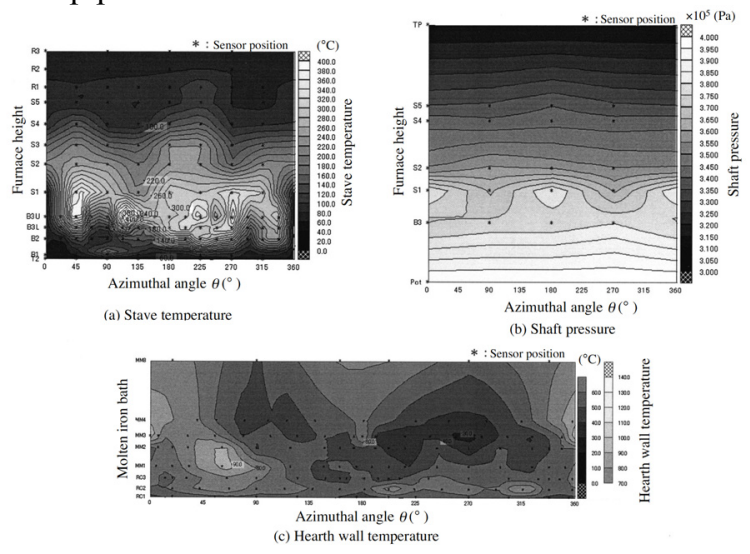

Fig. 3. Visualization examples of stave temperature, shaft pressure and hearth wall temperature 
When these visual images are renewed at intervals, the non-steady behavior of the spatial distribution of the phenomena inside the blast furnace can be quantified and visually shown in the form of moving images.

As visualization examples corresponding to the time trend chart of Fig. 2, Fig. 4 shows time trends in the distribution of stave temperature and shaft pressure in the furnace height direction.

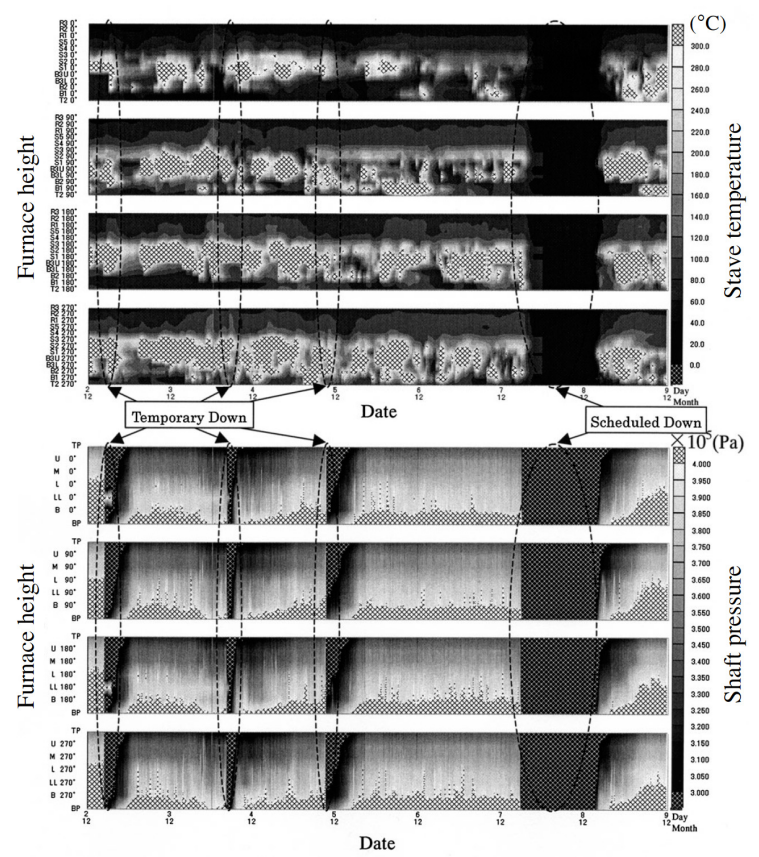

Fig. 4. Time trends of in height direction distribution of stave temperature and shaft pressure

\subsection{Spatial differential vector of shaft pressure (Ito et al., 2003)}

Because the shaft pressure is not necessarily as great as the change, the operator usually manages using the space difference value of the pressure. With respect to this, we attempted to estimate the positions of the upper and lower boundaries of the cohesive zone root, using the spatial differential vector of shaft pressure defined by its 3-dimensional distribution.

On this assumption, the spatial differential vector of shaft pressure, which corresponds to gas flow, was selected as the item for the secondary manipulation of the visual information data, and its spatial distribution was visually projected onto a 2dimensional plane with coordinates of furnace height and azimuthal position (see Fig. 5.).

As a result, the upper side of the region, which was considered to correspond to the upper side of the cohesive zone root, was distinguished as a region with a large vector (the white-hatched areas in Fig. 5) and a small angle of deflection, and its lower side as a region showing a small vector and a large angle of deflection.

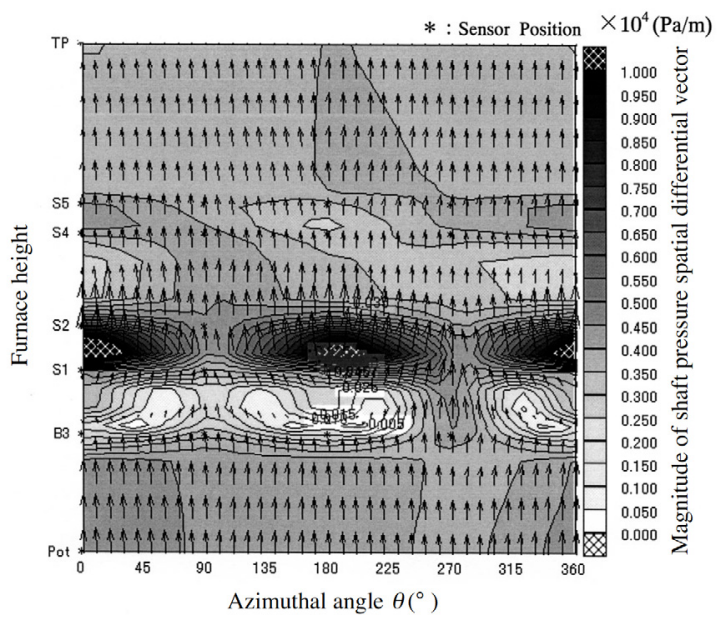

Fig. 5 Spatial distribution of the spatial differential vector of shaft pressure

That is, using shaft pressure $P_{(h, r, \theta, t)}(\mathrm{Pa})$ in position "a" (height $\mathrm{h}$, furnace radius $\mathrm{r}$, azimuthal angle $\theta$ at time $\mathrm{t}$ ) and tangential plane "A" at position "a" with height tangential axis $y$ and circumferential tangential axis 1 (see Fig. 6), the above vector was defined as a vector that included, as a component, the partial differential coefficient of shaft pressure $P_{(h, r, \theta, t)}$ at position "a" as in Equations (1) to (3) below, and with this, the measurement data were visualized and expressed in the form of a vector chart.

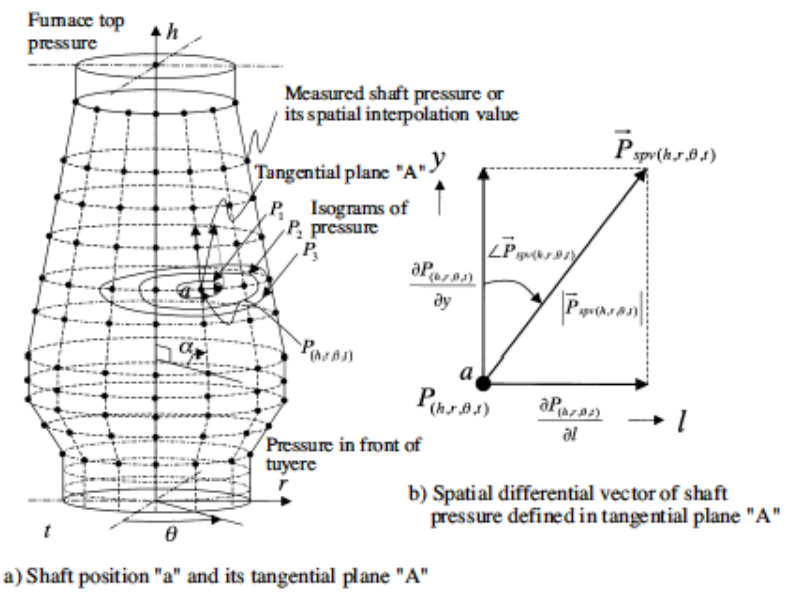

Fig. 6. Definition of spatial differential vector of shaft pressure

$$
\vec{P}_{s p v(h, r, \theta, t)}=\left\{\frac{\partial P_{(h, r, \theta, t)}}{\partial l}, \frac{\partial P_{(h, r, \theta, t)}}{\partial y}\right\}
$$

1) Magnitude of the spatial differential vector of shaft pressure

$$
\left|\vec{P}_{s p v(h, r, \theta, t)}\right|=\sqrt{\left(\frac{\partial P_{(h, r, \theta, t)}}{\partial l}\right)^{2}+\left(\frac{\partial P_{(h, r, \theta, t)}}{\partial y}\right)^{2}}[\mathrm{~Pa} / \mathrm{m}]
$$


2) Angle of deflection of the spatial differential vector of shaft pressure

$$
\angle \vec{P}_{s p v(h, r, \theta, t)}=\tan ^{-1}\left(\frac{\frac{\partial P_{(h, r, \theta, t)}}{\partial l}}{\frac{\partial P_{(h, r, \theta, t)}}{\partial y}}\right)[\mathrm{rad}]
$$

where the angle is defined as positive in the clockwise direction around height tangential axis y.

$$
-\pi[\mathrm{rad}]<\angle \vec{P}_{s p v(h, r, \theta, t)} \leq+\pi[\mathrm{rad}]
$$

Note that the magnitude of vector $\operatorname{Pspv}_{(h, r, \theta, t)}$ corresponds to a spatial expansion of the conventional indicator of shaft pressure drop $\Delta P / L(\mathrm{~Pa} / \mathrm{m})$

\section{Application example to blast furnace non-steady} phenomena

Figure7 shows an example of the transition chart for observation of the blast furnace operation that has been used so far. If it is a regular operation, it is preferable that the shaft pressure does not change in the time series.

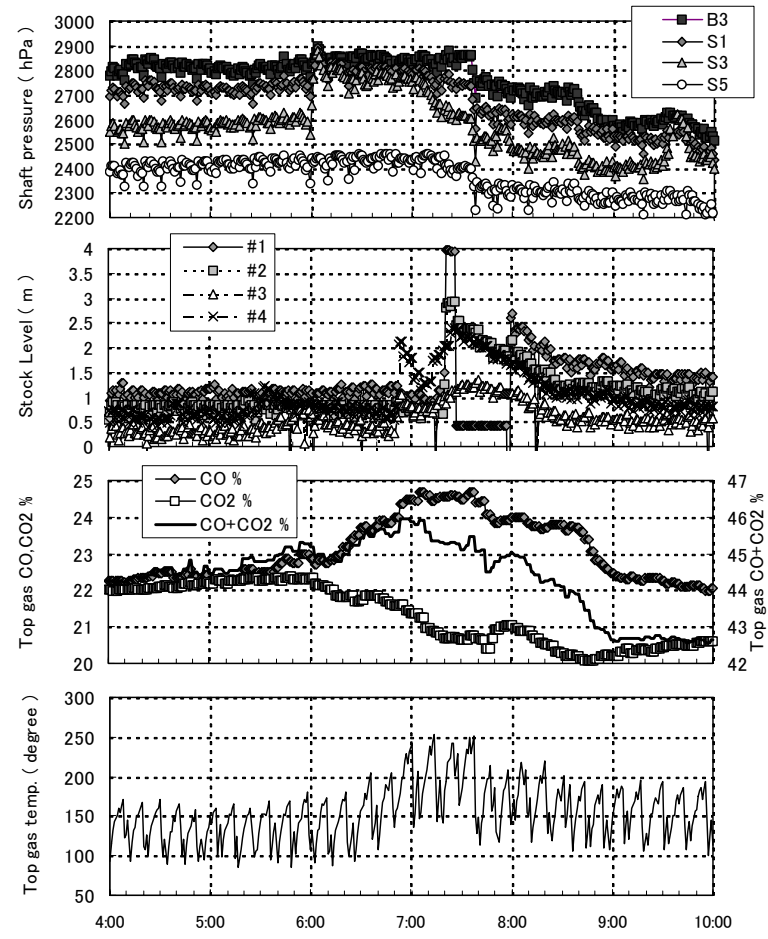

Fig. 7. Example of unstable operation data

From Fig. 7, it can be seen that the range of change is wide between 6:00 and about 8:00. Moreover, the exhaust gas element in the furnace top also changes greatly, and it is estimated to be exhausted from the furnace top at high temperature without the fluidizing area being generated in a specific in-furnace part; the filling of the charging material becomes sparse full, and the reduction gas reacts sufficiently with ore.

Thus, a non-stationary change that takes place in the furnace of the blast furnace by analyzing the operation transition chart can be assumed to some degree. However, it is difficult only using this information to assume space or behavior in the direction of the height of the furnace or in the direction of the circumference that changes timewise. Therefore, analysis of the two-dimensional behavior was conducted for the continuous data, the stave temperature and the shaft pressure to obtain spatial information on the two dimensions.

Figure 8 shows the differential pressure distribution in the shaft, and the distribution of the temperature of the stave at the time corresponding to the transition chart of Fig. 7 every 90 minutes from 4:00. From Fig. 1 , it can be seen that the shaft pressure increased at around 6.00, and slipping occurred at about 7:20. On the other hand, when there was shaft pressure distribution (Fig. 8.-a)), the pressure under the furnace increased rapidly between 5:30 and 7:00 in the direction of $0^{\circ}$. Moreover, unbalanced pressure distribution in the direction of the circumference remained, although there was an increase in pressure under the furnace after it slipped at 8:00. The cause of the pressure fluctuation is not considered completely removed. As for the temperature of the stave (Fig.8.-b)), the temperature increased at $0^{\circ}$ and in the direction of $360^{\circ}$ at 7:00, and a relation with the increasing shaft pressure was seen. A fluidizing area was generated in a specific in-furnace part at about 5:30 if this information was arranged, and it is believed that the filling of the charge changed greatly. Moreover, the density of CO increased from 5:00 when a change in the gas chromatograph data was observed from this viewpoint, and fluidizing started to occur.

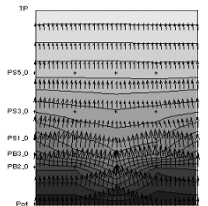

4:00

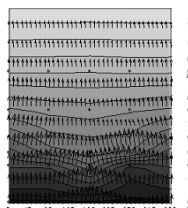

5:30

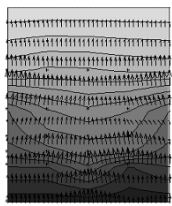

7:00

a) Shaft pressure $(\mathrm{hPa})$

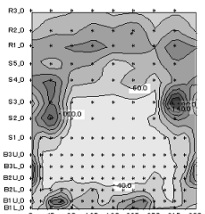

4:00

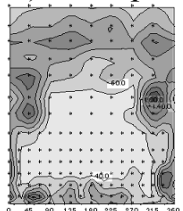

$5: 30$

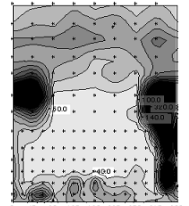

7:00

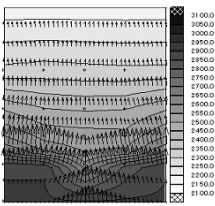

$8: 30$ b) Stave temperature(degree)

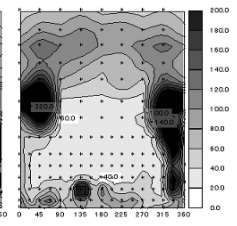

$8: 30$

Fig. 8. Time trends in visual image of sensor data

Thus, we can easily understand spatial changes in the in-furnace direction of the height and direction of the circumference and time transitions by making the 
temperature of the stave, the pressure distribution, and the analytic value visible in 2 dimensions. Moreover, earlier, more accurate detection becomes possible using shaft pressure fluctuation together with the sensor in the furnace top.

\section{CONCLUSION}

An image of the entire operating conditions of blast furnaces, which have so far only been conjectured, relying on the reasoning of experienced furnace operators and based on measurement data at a certain instant as well as time trend charts, can be seen as objective visual information as a result of developing a visual evaluation and numerical analysis system for blast furnaces.

The developed system has made it possible to quantitatively evaluate the non-steady behavior of the spatial distribution of phenomena inside a blast furnace, and it has been applied to the operation supervision of commercial blast furnaces.

We intend to further develop, by verifying the effectiveness of the developed system through application to actual furnace operation, a technique to quantitatively evaluate the non-steady behavior of phenomena inside blast furnaces, which show spatial distribution of their characteristics, and a new modeling technique as well as a system of operating it flexibly and adequately.

\section{REFERENCES}

Ito, M. and S.Matsuzaki (2002). Development of the visualizing system of the blast furnace process data-1. CAMP-ISIJ. 15, 927

Ito, M. and S.Matsuzaki (2003). Development of the visualizing system of blast furnace process data3. CAMP-ISIJ. 16, 300

Niwa, Y., T.Sumikame, M.Sakurai and T.Aoki (1989). Development of expert system and its problem on blast furnace heat control. CAMPISIJ. 2, 22

Matsuzaki, S. and M.Ito (2002). Development of the visualizing system of the blast furnace process data-1. CAMP-ISIJ. 15, 928

Nogami, H. (2003). Improvement of mathematical model of blast furnace and its application in practical operation. Tetsu-to-Hagane. 89, 211

Sugiyama, T. and M.Sugata (1987). Development of two-dimensional mathematical model of blast furnace "BRIGHT". Seitetsu Kenkyu., 325,34

Takatani, K. (1995). Recent development of the mathematical models of blast furnace. Tetsu-toHagane. 81, 1031

Takatani, K., T. Inada and Y.Ujisawa (1999). Threedimensional dynamic simulator for blast furnace. ISIJ Int. 39, 15
Takarabe, T., T. Nakamori, H. Oda, M. Taira, S. Watanabe and M.Seki (1989). Application of artificial intelligence to the operation control systems of the blast furnace No.3 and 4 at Kimitsu Works. CAMP-ISIJ. 2, 18

Yagi, J. (1983). Mathematical models of blast furnace. Tetsu-to-Hagane. 69, 1242 